TRANS · núm. I9.I · 2015

MONOGRÁFICO $\cdot$ 11-14

\title{
Interpreting
}

\section{in Legal Settings, an Introduction}

JesÚS BAIGORRI JALÓN

Mariachiara Russo

Alfaqueque Research in Interpretation Group 
Legal interpreting is perhaps one of the widest-ranging and most challenging fields of activity for a professional interpreter. One sometimes feels hardly prepared to tackle the sheer variety of judicial cases, terminological and situational complexities or implications that may crop up at every assignment. Yet, despite the high-stakes risks entailed by an interpreter's performance, at the dawn of the third millennium we are still grappling with the lack of stringent regulations obliging national authorities to guarantee the provision of qualified interpreters for all parties and stages in a judicial proceeding. Consequently, there are still too many instances of miscarriage of justice associated to poor or totally absent interpreting services. This is not certainly the case in multilingual supranational institutions like the Court of Justice of the European Union or the International Court of Justice of the United Nations, where staff and free-lance interpreters are recruited according to strict quality controls, but it is far from infrequent, as the media often report, in other legal or law enforcement settings, such as immigration offices, prisons or police stations, whose sphere of activity have a bearing on court procedures.

Regarding criminal law, the premises for a fair trial are laid down in national Codes of Criminal Procedure which state that linguistic assistance is free and available when necessary. This is the case of Italy and Spain, and in the recent Directive 2010/64/EU of the European Parliament and of the Council which envisages the right to interpretation and translation in criminal proceedings stressing the prerequisite of quality. This Directive in particular raised great expectations among different stakeholders, who believe it will contribute to redress national bad practices, but as highlighted by some contributors to this volume those

expectations have only partially been fulfilled, particularly in the areas of interpreter training, accreditation and recruitment.

The present issue of TRANS aims at providing an overview of the legal, professional and interactional dimensions of interpreting in legal settings both at European and at national levels with cases from various countries including Italy and Spain. It should be seen as a compilation of various pieces of research which echo voices from different backgrounds that combine the expertise of being practitioners and researchers.

The volume begins with Erik Hertog's Looking back while going forward: 15 years of legal interpreting in the $E U$, where he makes an insightful contribution on the regulatory framework and the profession by taking stock of 15 years (1999-2014) of European and national legislation, of academic activity in training and research and of professionalization of the legal interpreting and translation community, highlighting important objectives that have been achieved.

Legal interpreting from the perspective of a professional interpreter who works in a multilingual institution is offered by Marina Pascual Olaguíbel in her La interpretación en el Tribunal de Justicia where she provides an account of the characteristic features of an interpreter's work in that specific context with particular reference to ethical considerations, types of users, role of mediation and the case preparation phase, which is a key element of interpreting at the Court of Justice.

The next contributions are extensive reports of three important research projects funded by the DG Justice with extremely far-reaching social implications.

The first is the European IMPLI project, The IMPLI project, pre-trial interpreting in Italy and the transposition of directive 20I0/64 EU 
by Amalia Amato and Gabriele Mack, which aims at improving interpreter training by gaining a better understanding of the interviewing techniques used by law enforcement agencies and prosecution services and at facilitating their mutual cooperation by informing them about interpreting techniques. The authors discuss some of the most relevant aspects of interpreting for the police in Italy, highlighting strengths and weaknesses, and draw a comparison with other countries involved in the project.

The second one is the European $\mathrm{Co}-\mathrm{Mi}$ norIN/QUEST project, CO-MinorIN/QUEST: Improving interpreter-mediated pre-trial interviews with minors by Heidi Salaets and Katalin Balogh, which studies the interactional dynamics of interpreter-mediated child interviews during the pre-trial phase in criminal procedures where the child, as a vulnerable interviewee, needs very special consideration. The authors provide the results of an online questionnaire distributed in six EU Member States to interpreters, police and justice officials, and child support professionals involved in child interviewing.

The sos-VICS project, involving nine Spanish universities, is the object of the next contribution by María Isabel Abril Martí, La interpretación en contextos de violencia de género con referencia al caso español. She first deals with the concept of gender violence in the Spanish and international legislative framework, and then describes the project aimed at detecting the need for language mediation offerered by specialised interpreters in public services and at producing informative and training material for interpreters, law-enforcement agents and victims involved in gender violence.

The next two contributions focus on language mediation services in two specific Italian settings. Mette Rudvin and Francesca Pesare in their contribution Language Mediation for Victims of Human Trafficking at Detention Centres for Undocumented Migrants. The Case of the CIE in Bologna, discuss a series of functions performed by language and cultural mediators in detention centres ranging from providing practical information, in addition to language mediation, to more sensitive roles like offering emotional and psychological support. They show how the mediator's tasks in these settings differ from those carried out by language mediators in most of the other legal domains (especially courts), where discourse is usually formal and 'ritualised'. The mediator's roles in this case study resemble those found in spheres where unpredictable intense emotional stressors are common features, such as in refugee or prison settings or in the police preliminary investigation stages.

The next contribution deals with interpreter-mediated telephone tapping. In Interpretar escuchas telefónicas en ámbito judicial: análisis descriptivo y metodología operacional, María Jesús González Rodríguez analyses the interpreter's role and modus operandi in this specific communicative setting and the complexities of the linguistic and pragmatic codes involved. Starting from the observation of her long-standing personal professional experience, the author suggests a comprehensive methodology for the benefit of practising interpreters and users of interpreting services alike.

The last contribution epitomises the spirit and basic assumption that runs through the whole volume, namely that interpreting in legal settings can be of good quality only if performed by qualified interpreters fully aware of their roles and limits, supported by a regulatory framework that duly safeguards and certifies professionalism. Juan Miguel Ortega Herráez in Reflexiones en torno al binomio formación- 
ब禇 acreditación como elementos constitutivos de la profesionalización de la interpretación jurídica carries out a detailed analysis of documents, procedures 14 and publications concerning professional certification of legal interpreters in Spain and other countries, and the role of specialised training to guarantee a quality performance.
We hope that this volume will provide a stimulating insight into interpreting in legal settings for researchers, trainers, professional interpreters, interpreting students and users in public services, where there is still a long way to go before the demand for qualified interpreters is adequately met. 